\title{
metamorfose literária: por leituras que gerem experiências de pensamento nas
}

\author{
aulas de filosofia
}

adriana gusmão antunes ${ }^{1}$

universidade federal do espírito santo, brasil orcid id: https:/ / orcid.org/0000-0002-2029-8401

jair miranda paiva ${ }^{2}$

universidade federal do espírito santo, brasil orcid id: https:/ / orcid.org/0000-0002-6986-3213

\section{resumo}

O presente artigo compartilha uma experiência filosófica vivenciada a partir do acompanhamento e relato de uma aula de filosofia e da questão: que pode uma obra literária/leitura(s) suscitar como uma experiência de pensamento numa aula de filosofia? Seguindo a reflexão do como o ato da leitura literária pode constituir-se viés proponente para principiar experiência de pensamento, fio condutor de um diálogo que movimentará a roda da conversa, dialogamos e traçamos um caminhar paralelo ora por metáfora, ora por comparação, entre o relato dessa experiência vivenciada na escola da rede pública municipal e a transformação/metamorfose da borboleta. A partir de então, projetamos num dizer poético a leveza, o convite para o voo, para possibilidades de perder o chão a fim de ganhar e habitar nos ares que dá, literalmente, voz a uma criança do primeiro ano com provável diagnóstico de autismo, há seis meses inserida no ensino regular, que não falava em público. Pensando a experiência conforme Larrosa como algo que afeta, perpassa, "isso que me passa", e o pensar na escola pública a partir de Kohan, como sendo esse um dos paradoxos imperativos e preocupação primeira das práticas educacionais, perseguimos o objetivo de apresentar a filosofia para/com crianças como uma possibilidade real de oportunizar o romper de casulos, a concretização de um ciclo da metamorfose de uma infância ou da própria educação no/para o pensar; apresentamos, enfim, a importância da filosofia na/para a educação, sendo ela literariamente a oportunidade para estimular o pensar.

palavras-chave: escola pública; leitura literária; filosofia; ensino; experiência.

\section{metamorfosis literaria: por lecturas que generen experiencias de pensamiento en las clases de filosofía}

\section{resumen}

El presente artículo comparte una experiencia filosófica vivida a partir del acompañamiento y relato de una clase de filosofía y de la pregunta: ¿qué puede una obra literaria/lectura(s) suscitar como experiencia de pensamiento en una clase de filosofía? Siguiendo la reflexión de cómo el acto de la lectura literaria puede constituirse en un planteamiento para comenzar una experiencia de pensamiento, hilo conductor de un diálogo que pondrá en movimiento la rueda de la conversación, dialogamos y trazamos un caminar paralelo ya por metáfora, ya por comparación, entre el relato de esa experiencia vivida en la escuela de la red pública municipal y la transformación/metamorfosis de la mariposa. A partir de ésto, proyectamos en un

\footnotetext{
${ }^{1}$ E-mail: adrianagusmaoprofe@hotmail.com

2 E-mail: jmipaiva@gmail.com
} 
metamorfose literária: por leituras que gerem experiências de pensamento nas aulas de filosofia

lenguaje poético la ligereza, la invitación al vuelo, a posibilidades de salir del suelo a fin de ganar y habitar en los aires que da, literalmente, voz a un niño de primer año con probable diagnóstico de autismo, hace seis meses incorporado en la enseñanza regular, que no hablaba en público. Pensando la experiencia de acuerdo con Larrosa como algo que afecta, que se impregna, "eso que me pasa ", y el pensar en la escuela pública a partir de Kohan, como una de las paradojas imperativas y preocupación primera de las prácticas educacionales, perseguimos el objetivo de presentar la filosofía para/con niños como una posibilidad real de propiciar la eclosión de capullos, la concreción de un ciclo de metamorfosis de una infancia o de la propia educación en/para el pensar; presentamos, en fin, la importancia de la filosofía en/para la educación, siendo ella literalmente la oportunidad para estimular el pensar.

palabras clave: escuela pública; lectura literaria; filosofía; enseñanza; experiencia.

\section{literary metamorphosis: by readings that generate thought experiences in philosophy classes}

\section{abstract}

This article discusses a philosophical experience that occurred through observing and writing an account of a philosophy class with this question in mind: What can a literary work/reading evoke as an experience of thought in a philosophy class? We attempt to answer this by reflecting on how the act of literary reading can constitute a proponent bias to initiate an experience of thought, common thread of a dialogue that will drive the entire conversation. To this end, we dialogue and delineate a parallel path, based on a comparison between the account of this experience in a municipal public school and the transformation/metamorphosis of a butterfly. We then seek to convey through poetic language a lightness, an invitation to fly, to enable us to leave the ground and inhabit the air that literally gives voice to a first grader, probably autistic, who had spent the last six months in regular classes, but who did not speak in public. We see experience as Larrosa does, as something that affects, that passes through, "this that happens to me," while we adopt Kohan's view of thinking in public schools as one of the mandatory paradoxes and primary purposes of education. In so doing, our goal is to present philosophy for/with children as a real possibility to enable leaving a cocoon, the bringing to fruition of a cycle of metamorphosis from childhood or from education itself in/to thought. This article thus argues in favor of the importance of philosophy in education, since it literally provides the opportunity to stimulate thought.

keywords: public school; literature reading; philosophy; teaching; experience. 
metamorfose literária: por leituras que gerem experiências de pensamento nas aulas de filosofia

\title{
introdução
}

\begin{abstract}
"O desafio se dá em cada pensamento, em cada leitura, em cada escritura, em cada vez que se entra em uma sala de aula[...]" (Kohan, 1999, p. 85).
\end{abstract}

Emprestamos a esse artigo a nomenclatura/título de uma obra no prelo intitulada Metamorfose Literária, na qual a autora, seja em prosas ou em versos, discorre sobre algumas experiências vivenciadas nas classes em que lecionou a disciplina de Língua Portuguesa e Literatura em escolas da periferia de São Mateus, ES, Brasil; experiências nas quais a leitura e a escrita foram ora os motes de hibernação, ora a força para romper casulos que aprisionavam os alunos mas, também, significava oportunidade encontrada para esticar asas e alçar voos.

Principiemos essa introdução compartilhando que essa escrita é resultado de um afetamento pela experiência da educação filosófica no município de São Mateus, ES, na potência proposta por Larrosa (2011, p. 04-27), de experiência que me perpassa, afeta, inquieta. Assim, a compartilhamos sob a ótica de uma metamorfose que acontece quando o paradoxo entre o ato de ensinar e aprender inquietam tão intensamente, que se transformam e transbordam em palavras dispostas sobre uma lauda, numa junção de signos que tentam (re)viver e dialogar com a pluralidade das coisas que acontecem; que " $m e$ " afetaram, ainda no sentido de Larrosa, e afetam a disposição para o ato de investigar a experiência de pensamento na/para a infância no espaço escolar.

Tudo começou quando ousamos trazer para nossa pacata cidade interiorana um Congresso Internacional e, unindo forças, Secretaria Municipal de Educação de São Mateus, Universidade Federal do Espírito Santo (UFES, campus São Mateus), Faculdade Vale do Cricaré e Nefi (Núcleo de Estudos de Filosofias e Infâncias) da UERJ (Universidade do Estado do Rio de Janeiro) - sob a coordenação de Prof. Walter Kohan, fizemos acontecer o Seminário Internacional educação filosofias infâncias: "Filosofar com infâncias: resistir na escola" (Semfili), 
metamorfose literária: por leituras que gerem experiências de pensamento nas aulas de filosofia

entre os dias 15 a 18 de agosto de 2018, momento ímpar que a filosofia caminhou não apenas pelo campus da Universidade, mas também pela praia de nosso balneário, pela instituição privada, pelas ruas, por nossas escolas, tanto urbanas quanto campesinas.

Como membros da equipe organizadora, participamos de uma experiência de pensamento desenvolvida na rede pública municipal de São Mateus, em uma classe do primeiro ano do Ensino Fundamental 1 (anos iniciais), situada no Bairro Cohab, perímetro urbano. Essa aula/experiência nos afetou de modo diferente, pois vimos e ouvimos uma criança ${ }^{3}$ dita "autista" (pois seu irmão já dispõe do diagnóstico de autismo e faz acompanhamento/tratamento com terapeutas) romper seu casulo e alçar voos pela experiência de pensamento. Nessa "aula", pudemos sentir e entender o filosofar que Kohan desenvolve em seus escritos (2009, 2010, 2016, entre outros), isto é, a potência paradoxal entre o ensinar e aprender filosofia no ambiente escolar, a potência desse paradoxo entre as posições de ensinante e aprendiz de filosofia, a intensidade e liberdade, a presença da tensão e a percepção de como a sala de aula quando conduzida por "um educador interessado em propiciar espaços de pensamento potentes, livres e abertos à transformação de si e dos outros [...] desencadeia um complexo jogo de forças no pensamento; afirma um modo de exercer o poder de e para pensar" (KOHAN, 2009, p. 10-11).

O professor de filosofia efetivo na referida escola é o filósofo Wanderson Martins Alves; todavia, como parte da proposta do Semfili de integrar escola básica e universidade, bem como estreitar laços entre profissionais de filosofia com crianças de escolas públicas de distintas regiões do país, fora sugerido que a experiência seria conduzida pelos professores visitantes que vieram para o Semfili e a turma do primeiro ano ficou sob a responsabilidade do pedagogo José Ricardo Pereira Santiago Júnior ${ }^{4}$ e uma aluna do curso de Pedagogia da UERJ, ambos integrantes do Núcleo de Estudos de Filosofias e Infâncias (Nefi) da UERJ, que

\footnotetext{
${ }^{3}$ A criança é filha de uma professora. Quando da experiência, suspeitava-se que ela também fosse portadora de autismo, visto que o irmão já estava em tratamento; agora, quando redijimos esse artigo, sabe-se que não é autista, apenas extremamente tímida. A chamaremos aqui de menino. ${ }^{4}$ José Ricardo Pereira Santiago Júnior é Mestre em Educação pela UERJ e Doutorando em Educação na UNIRIO.
} 
tem na coordenação geral o filósofo argentino Walter Omar Kohan, acompanhados por uma equipe pedagógica da Secretaria Municipal de Educação, para contribuir nos registros e outras tarefas necessárias.

Em um tempo cronológico de 120 minutos, José Ricardo propôs e coordenou uma experiência de pensamento composta e executada a partir do seguinte roteiro: tema - desejos/sonhos; disposição inicial - apresentação: desenhar em uma folha um desejo, que poderia ser algo pessoal ou que envolvesse mais pessoas - Exposição dos desenhos e verbalização do que representava o desenho; leitura do texto - obra literária Cosas que pasan ${ }^{5}$, da argentina Isol (2008): leitura pausada para apreciação das imagens; problematização - solicitou-se para que em grupos de três elaborassem uma pergunta com as palavras "como ou por que" e "desejo", seguida de leitura das perguntas e levantamento de eventuais respostas na roda; para continuar pensando - por fim, os participantes da experiência pegariam seu desenho inicial e presenteariam outra pessoa ali presente, para que cada um cuidasse do desejo do outro.

Para nós, compartilhar essa experiência de percepção prática da "roda de conversa" significou a possibilidade de deixar-nos provocar por uma leitura literária como narrativa potente para gerar o pensar, como uma história que gerou o pensar efetivamente, como, nesse texto podemos não apenas compartilhar mas, antes, experimentar. Narrativa essa que, concretamente, ressalta das folhas de celulose prensadas/pensadas cuidadosamente para encantar/alimentar que, sob uma ótica para além do ensino de conteúdo, nas mãos e na condução de um ensinante/aprendiz, se torna o alimento que fortalece a experiência e repousa no silêncio; naquele silêncio que, segundo Bakhtin (2011, p. 270-335), também dialoga consigo mesmo, que, quando se cala, ainda enuncia, pois é eco que ressoa, compartilha saber/experiência de diálogo, um diálogo dialógico consigo mesmo. Nesse sentido, a roda de conversa fez de nós aprendizes de infâncias que jogam e propõem experiências, sob o nome de filosofia, no campo do pensamento, conforme Kohan (2016).

\footnotetext{
${ }^{5}$ Breve sinopse transcrita da contracapa da obra: "Eu iria para a escola a galope, se tivesse um cavalo. Ela seria mais forte, mais bonita e mais alta, se seus desejos fossem satisfeitos. Um dia, um gênio aparece e lhe concede um desejo. Agora seu problema é escolher qual deles."
} 
metamorfose literária: por leituras que gerem experiências de pensamento nas aulas de filosofia

Então, nos propomos dialogar acerca do para quê ensinar filosofia, seu valor e sentido para crianças de uma escola pública. Ao mesmo, narramos o tempo, tomado como instante preciso, em que uma criança descobre, em uma aula de filosofia, que ela pode e consegue interagir com igualdade, em que sua voz ganha corpo, se prolonga e, com segurança, liberta-se de um longo período de hibernação, se lançando para sua metamorfose.

Nesse diálogo-experiência, agora tornado texto, tecido, com suas partes, tais como nervuras, folhas, fios de um tecido impossível de ser visto na totalidade, pois que se trata do que aqui tomamos como intraduzível, a experiência, optamos por desenvolvê-lo nas seguintes etapas (sabedores que a experiência ultrapassa em muito nossa capacidade de narrar...): na seção "porque lagartas se alimentam de folhas" narramos o acontecimento de estrangeiros na rotina de uma pequena escola do interior do Brasil, em que olhinhos inquietos os esperavam... Aqui tecemos considerações leves (de borboleta) sobre a folha de papel, o desenho em grupo, a leitura literária... A seguir, no subtítulo "casulos moldam asas..." acentuamos o poder das palavras e das brincadeiras com os signos literários na experiência do pensar, a partir das consignas e comandos de um professor mestre da experiência, mas também capaz de ouvir, abrir-se... No tópico seguinte, intitulado "o eclodir das asas - a metamorfose", descrevemos o instante transformador em que uma criança, estimulada na roda do pensar, sai do casulo e se transforma em ser falante... Aqui o núcleo deste texto-relato-metamorfose, em que a linguagem literária e a experiência do pensar com infâncias na escola pública, afetados e impulsionados pelas práticas, ideias, escritos e vida de Walter Kohan tomam vida, se fazem potentes... Por fim, ressaltamos no que se espera sejam considerações finais, mas que preferimos chamar "conclusões? metamorfoses, voos", o lugar de uma educação filosófica descolonizadora como tarefa infinita do professor de filosofia, nos colocando perguntas, antes de que certezas, tanto quanto no início do pensar, abrindo-nos, também, como a borboleta, a devires da experiência e do pensar...

porque lagartas se alimentam de folhas...

A comitiva foi calorosamente recepcionada com uma canção de 'bom dia e 
bem-vindos' na voz à capela pueril da turma, disposta em organização circular, já previamente informados que 'estrangeiros' à sua rotina escolar estariam visitando e querendo participar de uma aula de filosofia para experimentar como eles pensam o pensamento filosófico. Percebíamos olhinhos curiosos e irrequietos desejosos por conhecer, serem conhecidos... Ansiosos pela porção filosófica daquele dia.

A experiência se inaugura com a proposta de passear pela folha, de sentir o branco do papel, no exercício de dar cor e vida à celulose tratada para o uso escolar. Debruçadas sobre o piso, as crianças e os adultos ali presentes alimentam a folha com seus traços, cores, ensaiando fazer visível o pensamento, a ideia primeira que nutrirá seus pensamentos para o diálogo.

O desenhar requer cuidado e paciência para nutrir o traço, como fazem as lagartas que se alimentam das folhas, vagarosamente, por partes... ora só, ora em grupo, passeiam pela folha, extraindo os nutrientes que precisam para viver futuras experiências. No momento seguinte, desejos transfigurados no papel e na roda principiamos a compartilhar, digerir, socializar o que a ilustração simboliza para quem a fez.

Repousemos um pouco mais sobre a folha. Na língua portuguesa, esse vocábulo é bastante prolixo em sua significação e ato de nomear coisas; todavia, nosso pensamento se atem ao sentido botânico: como principal estrutura assimiladora do vegetal, a folha capta a luz e a transforma em um processo de fotossíntese, respirando com a árvore, expõe a ausência ou a presença de nutrientes suficientes no solo e se os mesmos a estão nutrindo. A folhagem expõe o escondido, comunica o estado de vida e como a seiva segue circulando pelo todo, a árvore... O desenho, agora no traço disposto sobre a folha de celulose que repousa no piso frio, também comunica o estado de nutrição e disposição para a experiência. É preciso vivificar algumas folhinhas 'murchas' que, agora, após a disposição inicial, seguem regadas pela leitura literária, acerca da qual María Teresa de La Garza (1999, p. 117) nos diz:

A partir do texto e de suas experiências, a comunidade constrói um novo texto, um tecido de sentido que se cria cooperativamente [...] a linguagem dá lugar a um saber que ultrapassa as fronteiras do reconhecimento de quem a emite. A linguagem é o universo simbólico no qual nós, os seres humanos, nos movemos [..]. 
metamorfose literária: por leituras que gerem experiências de pensamento nas aulas de filosofia

Quando a leitura da obra de Isol (2008), Cosas que pasan, ganha vida na roda e na voz do professor José Ricardo, sentimos que essa linguagem envolve a roda dos pequenos pensadores ao propor o desafio de pensar um pouco mais além, sair do próprio desejo e se perguntar: “O que será que a personagem pediu? Ela queria tudo!". Já não é mais o "meu", há um convite para se deslocar sobre o lido que, para Larrosa (2004, p. 328), é um momento singular, de experiência, seja “[...] talvez, a experiência da leitura, de remeter a leitura a uma experiência e não a uma essência, ou a uma atividade, ou a uma prática." Então, se caminha para uma relação de experiência com o texto, que chamamos de leitura, uma leitura conduzida pela literatura, um parar no texto...

\section{casulos moldam asas...}

Nesse repouso que conduziu as crianças, frágeis devoradoras de folhas, acontece o deslocamento, momento de reconfigurar os lugares na roda para pensar junto, nesse caso, em trio. Qual o tempo de hibernação de uma pergunta/afirmação/questão para a experiência? O professor dá o comando: elaborar uma pergunta com as palavras "como ou por que" e "desejo" - é momento de repousar sobre um casulo que, visto em primeira mão, aparenta fechar/encerrar-se sobre a questão. Acontece o revolver a leitura, o desenho, o estar com, o pensar junto... não é simples estar em trio, registrar apenas uma ideia, a do pensar (com)junto. Estimular o dizer pelo signo gráfico ainda não plenamente dominado por seus escreventes.

Todavia, é preciso entender que as asas de uma borboleta são geradas no casulo. E o tempo dessa hibernação molda delicadas e ágeis asas, nos casulos há uma beleza escondida... há uma agitação... os alunos estão eufóricos, surgem tensões... acordos, desacordos... é preciso registrar a pergunta do grupo com a palavra, pela palavra, grafando o signo. O que deseja esse professor quando pede a infantes ainda em processo de alfabetização que registrem sua pergunta com palavra? Por que delimitar quais palavras não podem 'faltar' na pergunta? De acordo com Kohan (1998, p. 97), o texto:

[...] é uma excelente ocasião para expandir a capacidade das crianças de perguntarem e porem o mundo em questão. Nem todas as perguntas têm o mesmo valor nem a mesma potencialidade filosófica, mas toda filosofia 
surge quando se problematiza o mundo e todo problema tem sua origem numa pergunta.

No processo de escolarização da criança e de sua incursão no mundo do saber e da cultura, nos quais quase sempre é enfatizado sobremaneira que pensar é conhecer e dominar os códigos com os quais se pode comunicar, a experiência filosófica nos mostra novos movimentos do pensar, do valor de aprender e ensinar a questionar, se questionar, questionar junto. Acerca desse processo, Olarieta (2013, p. 11-23) salienta: “As palavras nos ensinarão não só a dizer, mas também a ver, a pensar, a compreender as coisas e a compreender-nos de um modo particular." Ao brincar/pensar com as palavras a criança é estimulada a dizer coisas novas, a agir no mundo, a ser participante ativa na comunicação do pensamento pelo literário, pela/na palavra no sentido de uma enunciação coletiva. É também um (re)dialogar com a obra, nesse momento de moldar a partir do literário (como a borboleta molda sua asa no casulo) ao que Larrosa (1999, p. 122) nos faz perceber:

Poderíamos então dizer: 'entre' filosofia e literatura se abre um espaço de jogo no qual o que se joga é a relação entre escrita e experiência. E, então, entre literatura e filosofia, entre escrita e experiência, 'dar o que ler, dar o que pensar'.

Feita a pergunta, retornamos à roda, em que, presas ao signo impresso em parcas letras desenhadas no papel, as palavras hibernam... Trazem dentro de si todo um querer dizer, o desejo de se abrir para um real singular, exposto por Larrosa (2011, p. 18) como algo que "ultrapassa qualquer inteligibilidade, o que está sempre mais além de qualquer compreensão, o incompreensível".

Prossigamos então, para a leitura das perguntas e levantamento de eventuais respostas na roda.

\section{o eclodir das asas - a metamorfose...}

Existe um instante mágico em que um gesto propõe mais que palavras, comunica com potência mais do que signos gráficos. Uma mão que se levanta com o dedinho apontando para cima chama a atenção. Capturamos, congelamos, perenizamos esse momento em uma foto guardada com apreço. Percebemos um casulo se rompendo... Mas, explicitemos como se deu esse momento.

Houve um intervalo para o lanche. Após esse intervalo, retoma-se a 
metamorfose literária: por leituras que gerem experiências de pensamento nas aulas de filosofia

experiência, o momento filosófico com as crianças do primeiro ano. O professor lê as perguntas que as crianças elaboraram e uma dentre elas se destacou para o diálogo na roda: "Por que o desejo não se realiza?"6. Todos querem falar, as crianças vão sendo ouvidas e, ao meu lado, aquele menino. Tímido, levanta o dedinho. Percebemos o valor e a singularidade desse gesto, de sua exposição na roda... Todavia, estrangeiro às peculiaridades daquele pequeno, desconhecendo os fatos, percebemos que José Ricardo parecia não percebê-lo. Há uma intervenção da autora, apontando para o menino... Queremos apreciar as asas dessa borboleta que se estica para sair do casulo... Mas o professor não entende a angustiante razão dessa insistência que, com a inflexão da voz, chama a atenção do mestre que, pelo olhar, aparenta surpresa e incompreensão, visto que estava sendo democrático e ouvindo a todos. E novamente propusemos: "Professor, vamos ouvir o menino?". Então, ele diz: "A tia Adriana disse que o menino quer falar. Quem é? Fala, vamos te ouvir!".

Ficamos nos perguntando o porquê não gravamos essa primeira voz do menino... seu movimento de sair do casulo e ativar as asas, de se permitir lançar-se para o deslocamento, quando a experiência de pensamento atravessa e passa, exigindo ser voz... voz que não havia, silenciada... Ela aconteceu com potência para um infante, em especial para aquela criança, naquela manhã, durante o exercício filosófico.

No dizer do professor de filosofia daquela turma, ao dialogarmos sobre aquele momento, logo após o encontro: "O fazer a experiência provoca mais o professor que o aluno, ela passa a ser mais do professor que do aluno." Sim, quando aquela criança se abre, pede a fala e fala, pela primeira vez, somos nós os mais impactados com a beleza e valor desse movimento... O menino toma gosto, pede a palavra novamente, percebe que, dizendo, também experimenta ser ouvido, sente que fala algo importante... terá isso sido experimentado pela primeira vez na vida?

Essa metamorfose, esse momento de abrir as asas e deixar a voz voar em uma aula de filosofia, pelo som de uma voz inaudível durante tantos meses naquele grupo, nos mostra para que veio a filosofia para/com crianças desde

6 Doravante, todas as falas da experiência filosófica estarão destacadas em itálico. 
Matthew Lipman e seguidores (1997), que criam e divulgam a proposta como "educação para o pensar", mas, sobremaneira, impulsionada e lançada a outros caminhos pela voz socrática e singular de W. Kohan, que toma de Lipman a ideia de levar a filosofia às crianças e a transforma em levar a filosofia a pensar com as crianças, com toda infância possível e a ser escavada em cada um... Num processo em que se joga a vida, o afeto como potência de existir, devir outro...

Sabemos que não inauguramos uma experiência como metamorfose. Grandes escritores e músicos já o fizeram. Porém, procuramos tão somente compartilhar a ideia que Patriota (1999, p. 135) já enunciara sobre uma obra clássica da literatura infantil brasileira, do célebre literato Monteiro Lobato:

[...] que 'evoluir é passar duma coisa para outra muito diferente, como um grão de milho que vai evoluindo e vira pé de milho, broa de fubá ou Visconde de Sabugosa', ou como Emília, que de bruxa de pano vai evoluindo, vira gente e cérebro, que não se aperta ou se atrapalha, lá onde os maiores filósofos se apertam e se atrapalharam.

A própria escrita literária já desnudava metamorfoses/experiências que transportam, vivificam o fértil imaginário do infante, que transformam coisas comuns em brinquedos vivos, que falam, sentem, interagem. Uma infância que brinca ensinando e ensina o adulto a (re)aprender a compartilhar, a imaginar, a dar vida ao inanimado, a despertar sua criança infante enclausurada no adulto.

E, quando termina a aula, no tempo cronos do espaço escolar, a autora sente alguém "puxar", com leveza, e uma voz baixa e familiar se faz audível: "Tia Adri, tia Adri, você pode guardar meu desejo? Eu guardo o seu também!". Ela tenta controlar sua emoção... Preocupada em fotografar, não obedecera ao comando do professor José Ricardo: "Para a gente continuar pensando, agora cada um de vocês deve pegar o desejo que desenhou e entregar para um colega. Vamos!". Realmente, ela não trocara com ninguém... estava ainda consigo uma ilustração em que, braços enlaçados, expressavam o desejo de um abraço coletivo, de afeto para com o próximo... Então, ela responde sem titubear: "Claro, coleguinha! Guardarei com todo prazer! E fico orgulhosa de você querer guardar meu abraço! Obrigada por me escolher!". Fazemos a foto (uma selfie). Eternizamos aquele momento em que, desde então, é guardiã do desejo de um menino literalmente infante que, por seu desenho e escrita, eterniza a ocasião em que ele, como herói, mata um terrível monstro que queria pegá-lo... Ah, menino... agora com essas asas para onde você haverá de voar? 
metamorfose literária: por leituras que gerem experiências de pensamento nas aulas de filosofia

\section{conclusão? metamorfoses, voos}

Como principiamos, tentemos agora arrematar esse compartilhar de uma experiência com/para as crianças no ambiente escolar, pelas palavras do professor Kohan:

Pensar e praticar uma educação filosófica descolonizadora, - enigmática e paradoxal -, sensível às tensões que habitam a relação entre quem ocupa o lugar de ensinar e quem habita o espaço de aprender é não só um indispensável programa de investigação filosófica, mas, mais ainda, uma das tarefas mais infinitas de um professor de filosofia, se é que existem os 'mais' e os 'menos' habitando esse espaço infinito aberto, faz já muito tempo, por um tal Sócrates (2009, p. 85-86).

Para continuar voando/pensando essa educação filosófica que liberta/dá asas, é necessário, agora, aprender a sugar o néctar das flores, das múltiplas espécies cultivadas nos jardins/escolas e, então... fertilizar, exercitar o ato de dar e receber, fertilizar com delicadeza e constância para gerar o fruto. A partir desse ponto da metáfora/metamorfose, suscitar o pensamento de que a experiência não acaba, ela sempre oportuniza outras mais, outras novas, outras possibilidades para os que saem do casulo e se aventuram a serem alados...

Será o professor de filosofia essa borboleta que suga, fertiliza, dá oportunidade para que aconteçam novos ciclos? Ou serão os (as) alunos(as) a borboleta que suga, fertiliza, inquieta o professor e suas aulas para que eclodam novos ciclos? Ou, ainda, será a própria educação filosófica com as infâncias na escola pública e/ou nos espaços para a troca de experiência essa borboleta que desperta ao ser tocada e nos presenteia com um beijo suave e profundo, fertilizando-nos para uma nova experiência, a de gerar frutos inominados e abertos a metamorfoses outras...?

Talvez sejamos nós, os que amam dialogar sobre as experiências filosóficas e a literatura, os infantes peraltas que nos apresenta Castro (2010), em seu artigo "A arte de caçar borboletas":

Com seu olhar inconsciente e curioso, a criança vê imagens num espaço colorido onde novas figuras expressam um texto, uma língua muda, de sutil objetividade. Assim, o menino assume a essência da borboleta e ao mesmo tempo nela se reconhece, ao percebê-la com um ser que sofre. A solidão, a espera e a incompreensão dão as características da criança que vai buscar seus aliados no mundo das coisas. [...] Essas são as margens da infância que a memória faz emergir (CASTRO, 2010, p. 230-231).

Enfim, sejamos continuamente, ou a parte, ou o todo de uma metamorfose 
que busca na solidão da linguagem literária o alimento que nutrirá uma hibernação para romper casulos; ou, como borboletas, suguemos dessa linguagem o néctar que nutre professor e aprendiz no mundo das coisas escolares, que poliniza, que multiplica primaveras e outonos, que segue o vento e deixa-se acariciar/aquecer pelo olhar de quem já não pode mais voltar a ser o que era antes a cada nova experiência de pensamento.

\section{referências}

BAKHTIN, M. M. Estética da criação verbal. 6. ed. São Paulo: Editora WMF Martins Fontes, 2011.

CASTRO, C. M de. Arte de caçar borboletas. In: KOHAN, W. O. (Org.). Devir-criança da filosofia: infância da educação. Belo Horizonte: Autêntica Editora, 2010. p. 223-231.

GARZA, M. T. De La. Filosofia e literatura: uma relação estreita. In: KOHAN, W. O.; LEAL, B. (Org.). Filosofia para crianças em debate. 4, Petrópolis: Editora Vozes, 1999. p.111-118.

ISOL. Cosas que pasan (A la Orilla del Viento). $2^{\mathrm{a}}$ reimp. Ciudad Autónoma de Buenos Aires, Argentina: Fondo de Cultura Económica, 2008.

KOHAN, W. O.; WAKSMAN, V. Filosofia para crianças na prática escolar. 2, Petrópolis: Editora Vozes, 1998.

KOHAN, W. O. Filosofia: o paradoxo de aprender e ensinar. Belo Horizonte: Autêntica Editora, 2009.

KOHAN, W. O. Devir-criança da filosofia: infância da educação. Belo Horizonte: Autêntica Editora, 2010.

KOHAN, W. O. A necessidade do impossível: pensar, ensinar, ler... a filosofia de uma escola popular. Leitura: Teoria E Prática, 34 (67). Campinas, 2016. p. 13-25.

LARROSA, J. B. Dar a ler, dar a pensar... quem sabe. Entre literatura e filosofia. In: KOHAN, W.O.; LEAL, B. (Orgs.). Filosofia para crianças em debate. 4, Petrópolis: Editora Vozes, 1999. p. 119-129.

LARROSA, J. B. Linguagem e educação depois de Babel. Belo Horizonte: Autêntica Editora, 2004.

LARROSA, J. B. Experiência e alteridade em educação. Revista Reflexão e Ação, 19 (2), 2011, p. 04-27.

LIPMAN, M.; SHARP, A. M.; OSCANYAN, F. S. A filosofia na sala de aula. 2.ed. São Paulo: Nova Alexandria, 1997.

OLARIETA, B. F. O sol e as laranjas. Ou sobre o lugar onde as crianças e a poesia se encontram. Childhood \& philosophy, 9 (17), 2013, p. 11-23.

PATRIOTA, M. (). O que a literatura oferece à filosofia? In: KOHAN, W.O.; LEAL, B. (Orgs.). Filosofia para crianças em debate. 4, Petrópolis, RJ: Editora Vozes, 1999. p. 130138.

recebido em: 21.04.2019

aceito em: 24.05.2019 